\title{
El número cien de la revista Encuentro
}

C

n regocijo presentamos nuestra edición número cien. Celebramos la ocasión con entusiasmo pues nos confirma dos afortunadas realidades: la primera, que a través de los años nuestros colaboradores han mantenido su apoyo decidido a la revista; la segunda, que la UCA ha seguido apostando por el proyecto mientras otras universidades dejaron de financiar, o nunca financiaron ni financiarían una revista científica que no genera ingresos monetarios ni mercadeo para la institución. Por esas razones, celebramos el número cien con agradecimiento hacia nuestros colaboradores y hacia la Dirección Superior de la Universidad Centroamericana, que nos han brindado su apoyo, ánimo y respeto por muchos años.

Para que una revista científica sea posible se requiere de mucho trabajo invisible. No se trata de coleccionar propuestas, diagramar y enviar a la imprenta, o subir a la internet. Tiene que haber suficientes propuestas buenas, que se logran si un investigador ha podido contar con el tiempo necesario y acceso para leer las publicaciones relevantes y actuales, y un valioso tiempo para escribir y re-escribir un trabajo bien pensado. Tiene que haber investigadores con experiencia suficiente en un campo para saber si un manuscrito representa un aporte para las discusiones actuales; y estos investigadores deben de dedicar un tiempo importante para realizar adecuadamente su juicio sobre un manuscrito. Nuestra revista cuenta con la colaboración de 46 revisores. Gracias a ellos los autores obtienen consejos oportunos para mejorar sus manuscritos antes de publicarlos. Las revisiones a veces son muy detalladas y demandan mucho tiempo y atención.

Para que funcione le revisión tiene que haber una persona que pueda saber quién está capacitado para juzgar un manuscrito en particular, así como distinguir si un manuscrito puede, de hecho, ser revisado; es decir, si tiene la calidad mínima necesaria para ser publicable. Así mismo, antes de publicarse, cada manuscrito debe pasar por una minuciosa revisión que incluye, además de la corrección gramatical, la constatación de que en el texto se hace un uso correcto de la referenciación para evitar el plagio, y para garantizar la función informativa que debe tener un artículo respecto a cómo se ha utilizado el trabajo de otros investigadores. Además, la revista tiene que diagramarse atendiendo los detalles que requiere una publicación científica. Encuentro ha podido mantener su diagramación a cargo de una misma persona, quien sabe, por ejemplo, que cada cursiva, cada sangría, cada mayúscula o minúscula, tiene que respetarse. En fin, el trabajo esencial para garantizar la calidad de una revista científica no se puede visibilizar y mucho menos contabilizar, tampoco se puede describir en el actual remachado y superficial lenguaje de los indicadores.

Una revista científica también depende de la existencia de condiciones importantes. En el caso de Encuentro nuestras fortalezas son contar con una efectiva revisión de pares y con un equipo permanente que se ha capacitado en gestión editorial. La revisión de pares es efectiva porque la realizan personas con experiencia en investigación y publicación de punta, que a la vez conocen la realidad Centroamericana. $\mathrm{Su}$ apoyo es el resultado de años de colaboraciones investigativas entre la UCA e investigadores provenientes de otras instituciones en Nicaragua y fuera del país. Muchas relaciones iniciaron a partir de proyectos puntuales y florecieron para convertirse en redes permanentes de colaboración. La otra fortaleza, contar con un equipo básico y permanente, nos permite mantener una serie de detalles importantes de manera estable, lo que se pondría en riesgo si tuviéramos que pasar la revista de unas a otras manos con frecuencia. El equipo es pequeño pero comprometido y enfocado, y se ha beneficiado de capacitaciones brindadas por el proyecto INASP-PERii a lo largo de más de diez años.

En el escenario actual de publicaciones científicas nuestra posición es crítica de la obsesión desmedida con los rankings de revistas y el factor de impacto. Los datos bibliométricos no reflejan la capacidad de aporte de una revista para una comunidad de investigadores pues existen sesgos y omisiones que surgen inevitablemente del énfasis cuantitativo de esas mediciones, y de su visión favorecedora de las ciencias duras, la producción anglófona, y las dinámicas de publicación y citación del primer mundo (Estados Unidos e Inglaterra, sobre todo). Sin embargo, tampoco nos unimos a la postura de que todas las publicaciones son iguales y de que entre más revistas y más publicaciones existan, es mejor. Pensamos que la ciencia no se beneficia de generar montones de publicaciones, lo que produce un círculo vicioso en el que los investigadores publican antes de estar listos para decir algo, los revisores no se interesan en evaluar con exigencia, las revistas publican artículos que carecen de originalidad, y los lectores ni siquiera piensan en consultarlas pues simplemente hay demasiadas. Es frecuente hoy en día encontrar revistas que, aún indizadas - particularmente en catálogos latinoamericanos-, se encuentran plagadas de errores de redacción o descuidos de varios tipos, y contienen artículos mediocres que sólo existen para ser carne de curriculum. Como resultado, pierden todos: los autores, la institución que respalda la revista, y los lectores. En ese contexto de extremos se mueve Encuentro, reconociendo que tenemos una responsabilidad con los autores y los lectores para perseverar como una revista que está para apoyarlos.

Wendy Bellanger

Editora 